\title{
www.czasopisma.pan.pl \\ Environmental Protection Versus Foundry Engineering Practice
}

\author{
M. Maj *, J. Werrtz, J. Piekło \\ Department of Engineering of Foundry Process, AGH University of Technology, \\ Reymonta 23, 30-059 Cracow, Poland \\ *Corresponding author. E-mail address: mmaj@agh.edu.pl
}

Received 07.11.2016; accepted in revised form 22.12.2016

\begin{abstract}
- Theory and practice of environmental protection in the case of foundries in Europe and Asia

- Experience resulting from the cooperation with the foundries in a few European countries, China and India

- Phenomena and factors affecting the pollution of the natural environment and the implementation of measures aiming at the environmental protection

Every specialist dealing with foundry processes and their impact on environmental pollution must have encountered in their professional careers numerous situations in which the theory of environmental protection confronts the stark reality. The discrepancy between theory and practice can particularly be noticed in foundry engineering in developing countries where the contrasts between different countries and casting plants are extremely striking. The comparison of working conditions in European and Asian foundries provides a vast scope for further observations and analyses. Environmental protection seems not only a concern of manufacturers of castings, but also of their customers whose opinion exerts a significant influence on both the acceptability of working conditions and on the approach to environmental pollution adopted in metal casting industry.

The article presents a number of examples of various outlooks on environmental issues in foundries manufacturing a wide range of cast steel and cast iron castings, where different technologies and production processes are applied.
\end{abstract}

Keyword: Environment pollution, Foundry industry, Comparison of environmental protection approach

\section{Polish Foundry Industry vs. European Foundries}

For years Polish Foundry Industry was associated with environmental pollution. In fact, most of the Polish foundries never paid attention to environmental protection requirements and it was treated as kind of standard. The reasons were well known: lack of adequate rules and disregard of influence of foundry activities on environment. Such approach as well as lack of sufficiently restrictive requirements applicable for the whole metallurgical industry caused difficulties in implementation of quite new environmental protection requirements. The inertness of managers and their resistance against implementation of new rules had the source in ownership of the foundries: almost all the foundries have been owned by government.

Then, while the European foundries were going to implement very restrictive limitations in application of harmful materials and processes, Poland were still far away behind them. Especially, Polish foundries were not forced to pay attention to gas and dust pollution as well as waste materials managements. The rules concerning installation of de-dusting systems and storage of waste do not exist at all or have been disregarded by foundries. The waste materials were mainly disposed to landfills. In several 
countries, reclamations of waste foundry and core sands became a standard, but the application $100 \%$ of a reclaimed sand as a matrix is rarely possible. A waste sand reclamation process allows recovering a sand matrix. In several foundry plants, in spite of having the reclamation installations, some amounts of moulding sands after a casting knocking out must be removed from a foundry plant and either managed outside it, or - in the last resort - stored. Most often this is moulding sand which was prepared already with a reclaimed sand fraction. Not all foundry plants have reclamation line [1].

The major change took place in years eighties of twenties century, when Polish foundries started to implement European rules concerning environmental protection. They were obliged strictly follow the rules given by water and air pollution international standards $[2,3]$.

What was as in the background the situation in Asian foundries?

\section{The different approach to the environmental protection problems in Europe and Asia}

First of all it should be pointed out that the main factor which determine that foundries in Asia comply with the environmental protection requirements or not, is ownership. It means that the division to private and government own foundries is clearly visible. The other factor which determines application of restrictive rules to manufacturing processes is the destination of the final product: it is intended for local market or for export. Last but not least, the important factor that influences the range of restrictions applicable for manufacturing processes is the pressure of the government and the general approach to environmental protection problems in certain country.

The European foundries work in conditions of strong competition, and under continues pressure of different Environmental Protection Organizations. They are forced to implement very restrictive rules and requirements, which are not comparable to rules applicable in Asia.

These requirements are still higher and higher, and they concern especially restrictions for water and air pollution as well as waste management issues.

The high cost of waste storage and utilization influences the competitiveness of European foundries significantly. As result, they cannot be really competitive to Asian foundries because of the casting prices.

When the all European foundries are hardly influenced by environmental protection rules and restrictions, the Asian market is very diverse. Deep analysis of the reasons of transfer of production and technology from Europe to Asian countries like India and China shows that the background of such decision is simple: production in Asia is in general not affected by environmental protection restrictions. Moreover, companies which transfer production from Europe to Asian countries did not exert pressure on Asian foundries to adapt the environmental protection rules. The countries like India and China still allow the companies to use predatory waste and material management due to the fact that they operate over a wide area (territory), touched by permanent lack of control from government.

Easy access to the place where the harmful waste materials can be stored without any control, lack of the estimation of the negative influence of such materials on environment, low cost of storage and the lack of penalties for pollution do not promote the activities favourable for preventing of environmental devastation. Such approach is much better visible in India than in China.

The main factors having a devastating impact on environment are: gas and dust pollution resulting from the metallurgical processes, moulding and core sand preparation processes, moulding and core making processes (it concerns especially chemically bonded sand), heat treatment processes, fettling and cleaning processes etc.

Mentioned above factors influencing the environment pollution are only the part of the many. Fortunately, the European customers of Asian foundries operate under the high pressure of Environmental Protection Organisations and they started to request the confirmation that the products they buy have been manufactured according to environmental protection rules. Such approach changes the situation of both European and Asian casting manufacturers [4]. The European customers have been quite quickly convinced that the quality of product of Asian foundries collapsed and the production cycle time was extended significant way. Then the delivery time has been changed and competitiveness of Asian foundries decreased significant way. European clients start to withdraw production from Asia, and a big part of Indian and Chinese foundries must restrict production to local market only.

The situation described above is favourable for European foundries, which may expect new orders for castings, especially in case of recovery in the market of energy suppliers. They are the biggest customers buying the large steel and nodular iron castings.

\section{Influence of working conditions on foundry activities concerning environmental protection}

Asian countries are characterized by an excess of manpower. It doesn't force the foundry owners to change and improve a working conditions of foundry staff. Especially in India we can face the problem of tough working conditions almost everywhere. People are working in conditions of high temperature, high humidity and very dusty air, and they are affected by worse illumination of working place as well. They usually are forced to work with primitive and worn tools and equipment. The castings produced in such tough conditions may not fulfil the high quality requirements. This in turn causes the poor financial condition of foundries and lack of resources for improvement. The loop is then closed. It concerns both the small and big foundries. The exceptions are the new private foundries built from the scratch, which are directed to production of steel and nodular castings for automotive and power industry (wind power, steam power).

Visiting the Indian foundries we may find the examples of very well organized and led foundries working according to the restricting environmental protection rules, and quite another places where the problem of environmental protection is 
completely ignored. The typical view of such foundry shows the phenomena related to running production - clouds of rust-brown smoke over the foundry roof, accompanying melting in electric arc furnaces (Fig. 1). Ventilation of the foundry hall is resolved the easiest possible way: smoke escapes through the big gaps between roof and foundry walls.

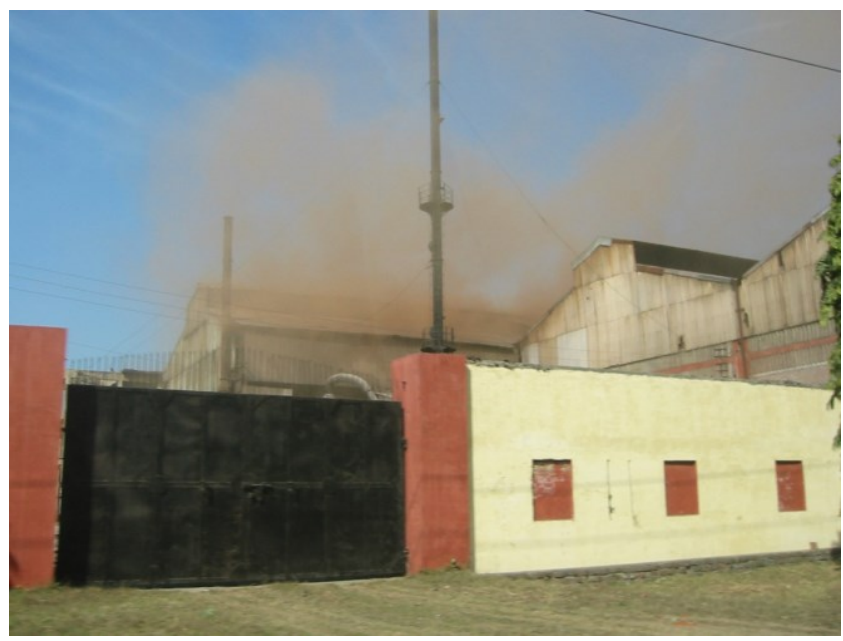

Fig. 1. UP Steel, Uttar Pradesh, India

Uninterrupted supply of fresh air from outside is also well secured (Fig.2 and 3).

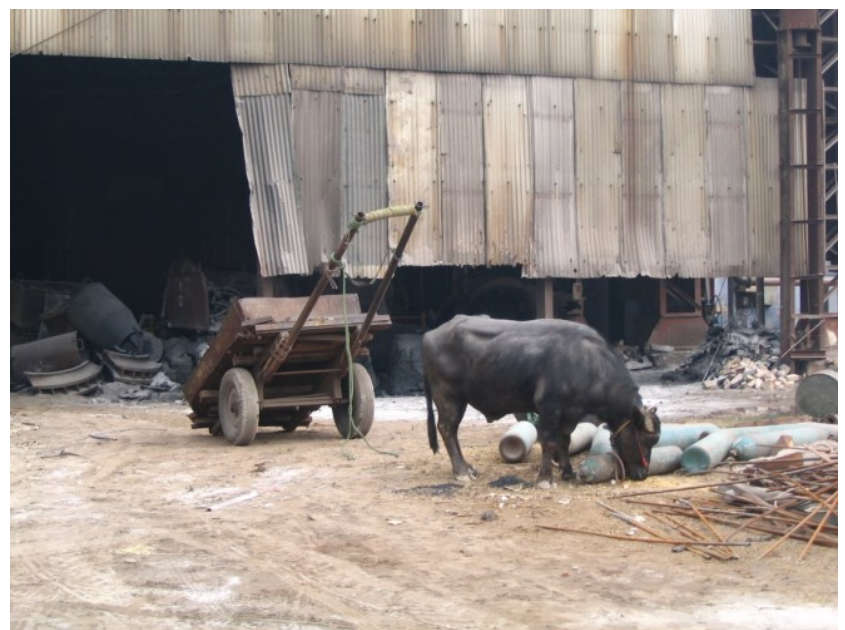

Fig. 2. UP Steel, Uttar Pradesh, India. Shakeout and cleaning section

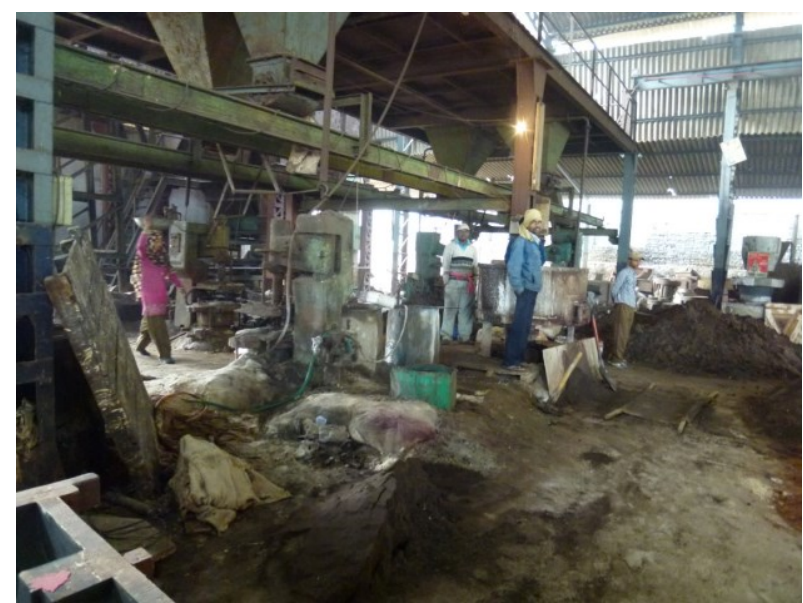

Fig. 3. Working conditions in small size private foundry. Unfortunately, such view can be relatively often found in India.

By contrast, In China in most foundries the halls and equipment are in good condition and the cleanness could be rather an unequalled model for European foundries [5, 6, 7, 8], (Fig. 4 , 5)

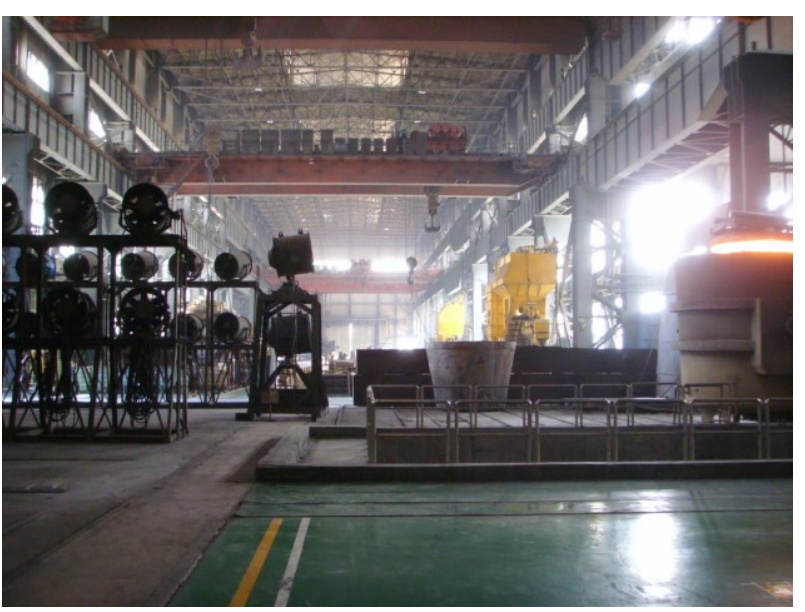

Fig. 4. DHHI foundry, Dalian, China

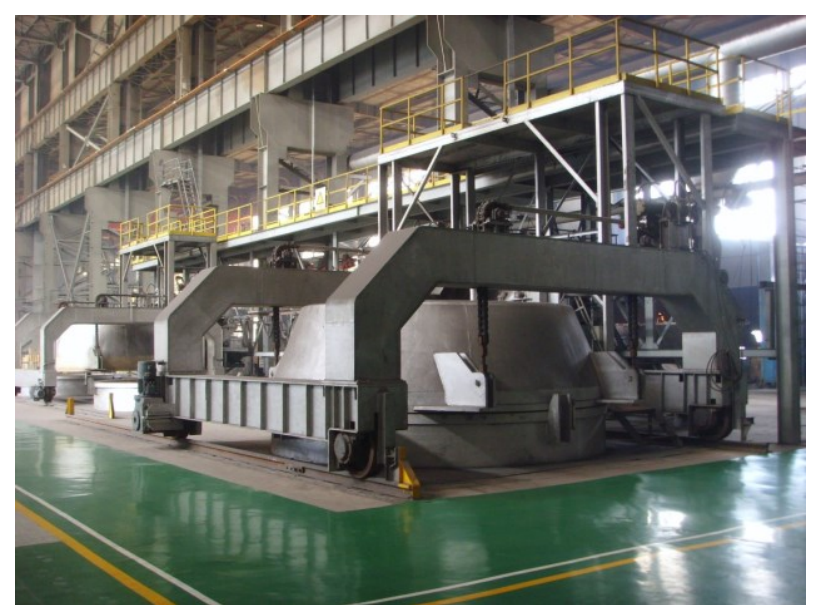

Fig. 5. DHHI foundry, Dalian, China 
No doubts, the Picture above have been taken in working foundry, having long tradition in manufacturing of large castings for heavy industry since 1914 (the DHHI Foundry is a part of Dalian Huarui Heavy Industry Group Co. Ltd.). Dalian City is the beloved place for Beijing citizens who travel there for weekends and holidays.

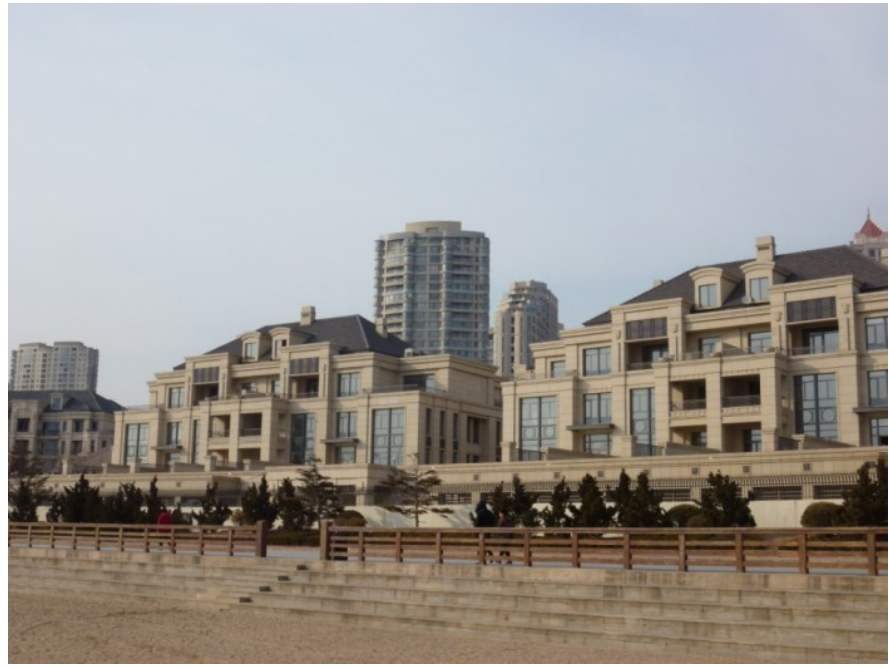

The major factor is the distance from Beijing to Dalian - ca. 1 hour flight only. Beside the harbour and industrial zone at seashore of Dalian placed are many private residences (built for party leaders) and hotels.

Fig. 6. Private residences and hotels at seashore, Dalian, China

In Europe we can also find places where foundry industry is located next to the famous resort areas. The best example is investment casting foundry Trucast Ltd. on the Wight Island, UK. Almost nobody knows that foundry works at area which is the ideal place used by UK citizens for weekends and summer holidays. The foundry must fulfil the most restrictive rules concerning environmental protection. These activities are so effective, that the majority of tourists have no idea that at this place works (since many years) investment foundry. The foundry belongs to Doncasters Group and within years its manufacturing processes have been modified several times. The harmful materials used for ceramic shells and wax models (lost wax casting technology), including alcohol-based binders were eliminated and replaced by non-toxic materials (e.g. water-based binders). Obviously, such politics caused increase of production costs and foundry was forced to cut costs and search for possibilities of saving. Due to logical, consequent government and implementation of the environmental protection rules foundry did not change their production profile and the foundry area was enlarged.

\section{Conclusions}

1) Foundry industry more and more effective fits into the casting manufacturing processes based on materials and technologies which guarantee minimised harmful influence on environment

2) European foundries use substantially the materials which undergo regeneration process, and it concerns especially moulding and core sand. Practically, no European foundry

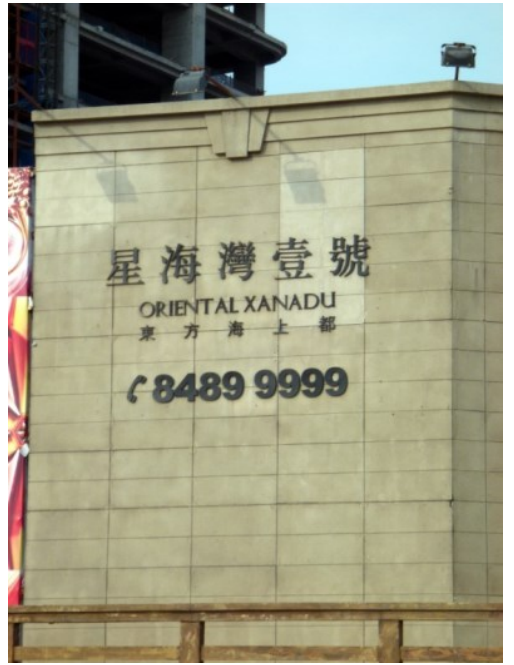

is allowed to work without sufficient sand regeneration facilities, independent on type of sand and method of regeneration.

3) To follow the environmental protection rules and requirements, European foundries give-up with application of currently forbidden traditional materials, as e.g. alcoholbased protective coatings, which are replaced by waterbased coatings.

4) Because of environmental protection requirements foundries have been forced to stop quenching of castings in oil, which is currently replaced by quenching in watersolution of polymers. However, this change requires several costly experimental works and cannot be implemented easily.

5) Due to the pressure from different organizations of environmental protection, the limitations of dust and air pollution touch also the Asian foundries.

6) The final product users (foundry customers) suddenly found the tool in their hands, to force the Asian foundry industry to take care on environmental protection problems. The good example of such activity is including in the contract agreement the condition that foundry may not use an asbestos in manufacturing processes.

Pictures: Fig $1-6$ taken by Authors

\section{References}

[1] Holtzer, M., Dańko, R. \& Kmita, A. (2016). Influence of a Reclaimed Sand Addition to Moulding Sand with Furan 
Resin on Its Impact on the Environment. Water, Air and Soil Pollution. vol. 227, ISSN 0049-6979.

[2] ISO 14001:2015; Environmental Management System (in Polish).

[3] Guide to the best available techniques (BAT) guidelines for the foundry industry, the Ministry of Environment September 2005. (in Polish).

[4] Vesuvius Foseco, Safety and environmental protection. (in Polish).

[5] ASIA INVEST - Technical Assistance- ASI/B7301/02/0535-004 (71307); Cleaner production in the foundry industry of the People's Republic of China; CENTRIC
AUSTRIA INTERNATIONAL - Center for Environmental Training and International Consulting,

[6] Murthy Sundara H. President The Institute Of Indian Foundrymen \& Fenfe Metallurgicals, Status Of Indian Foundry Industry, Bangalore, India Sep 22 '2010.

[7] Ms. Fan qi, Vice Secretary General, Status and Outlook of China Foundry Industry, China Foundry Association Sept. 2012,

[8] Gopal Padki , CEO Foseco China ,The Foundry Industry Trends in China: An evolution from volume to value path., Turkey Congress, Nov. 2006. 